\title{
Analysis of China's Pure Electric Vehicle Sales Based on Spatial Econometric Models
}

\author{
Huaying $\mathrm{Gu}^{1} \&$ Chaoqun $\mathrm{Han}^{2}$ \\ ${ }^{1}$ Logistics Research Center, Shanghai Maritime University, Shanghai, China \\ ${ }^{2}$ Business School, Shanghai Dianji University, Shanghai, China \\ Correspondence: Chaoqun Han, Business School, Shanghai Dianji University, 300 Shuihua Road, Pudong New \\ Area District, Shanghai 201306, China. Tel: 86-181-1636-2353. E-mail: 53001718@qq.com
}

Received: September 25, 2020

Accepted: November 15, 2020

Online Published: December 5, 2020

doi:10.5539/ijef.v13n1p12

URL: https://doi.org/10.5539/ijef.v13n1p12

\begin{abstract}
This paper empirically investigates the spatial dependence and serial correlation structures among different China's brands of pure electric vehicle (EV) sales using spatial econometric models. Based on the newly proposed economic distance spatial weight matrix, the empirical results show that EV endurance mileage, power battery capacity, charging time, government subsidy, retail price, and each brand market share have important impacts on EV sales. The per capita disposable income of urban households, gasoline price, loan rate and the number of charging pile are statistically significant determinants of EV sales. In particular, the improvements of the number of charging pile and the rise of gasoline price can increase EV sales, while the rise of loan rate or tight monetary policy may increase the consumers' cost of purchasing EVs and then decrease EV sales. Another interesting finding is that though the per capita disposable income of urban households increases the EV sales decreases. A plausible explanation would seem to be that the impact of the per capita disposable income of urban households on the EV sales is offset by the decline in government subsidies or the incomplete infrastructures such as the inconvenient of charging stations. Besides, the significantly positive spatial dependence and serial correlation exist among EV manufactures indicates that when developing EV sales strategies, EV manufacturers must consider not only the properties of the EVs they produce, but also the properties of similar types of EVs produced by other brands in the EV market.
\end{abstract}

Keywords: electric vehicle, sales, spatial dependence, serial correlation, spatial econometrics

\section{Introduction}

With the growing concerns about energy shortage and climate change, electric vehicles (EVs), which is regarded as one of the most for sustainable transportation, have widely attracted the attention of governments, energy industry, environmental enthusiasts, power companies, scholars and so on (Smith, 2009; Ahmadi, Yip, Fowler, Young, \& Fraser, 2014). However, the high cost, low capacity and short life of EV power batteries greatly reduce consumers' willingness to purchase EVs, which significantly restricts the healthy development of EVs (Heymans, Walker, Young, \& Fowler, 2014; Neubauer \& Pesaran, 2011). In recent years, the implementation of various types of EV incentive policies issued by governments around the world, for example, many governments provide subsidies for consumers, which have promoted the development of EVs (Avci, Girotra, \& Netessine, 2014; Carley, Krause, Lane, \& Graham, 2013; Schuitema, Anable, Skippon, \& Kinnear, 2013).

As the process of economic globalization accelerates, regional economies are increasingly connected to each other, and the change in a single economy will be transmitted to other economies through political, economic, and cultural channels. In this context, spatial econometric models are emerged as useful tools to study the spatial effects among different geographical or socio-economic units (Gu, Liu, \& Weng, 2017).

In fact, several studies on the adoption and influencing factors of EVs show that different countries or regions have heterogeneous characteristics due to their unique location attributes (Javid \& Nejat, 2017). The phenomena shows that understanding the nature of the dependence structure among different EV markets or EV brands holds important implications for EV manufacturers, policy makers, and academic researchers. On a practical level, the analysis of the dependence structure can help EV manufacturers construct optimal production strategy and can be beneficial for governments make reasonable EV subsidy policy. However, as far as we know, there are few 
literatures which use spatial econometric model to study the dependence structure among different EV markets or EV brands.

In this paper, based on spatial econometric models, the paper explores the spatial dependence and serial correlation structures among different China's brands of pure electric vehicle sales and analyzes the factors affecting China's pure electric vehicle sales. Meanwhile, the paper puts forward some suggestions on developing the useful sales strategies for EV manufacturers and making reasonable EV subsidy policies for governments.

The reminder of the paper is structured as follows. Section 2 introduces the existing literature in related study fields. Section 3 introduces the model specification and estimation methods. Section 4 presents empirical illustrations. The paper concludes with policy implications in Section 5.

\section{Literature Review}

\subsection{Adoption of Electric Vehicles}

The adoption of EVs has attracted more and more scholars' attention. Particularly, many scholars have conducted empirical research on the issue of the adoption of EVs. Generally, the research regions can be divided into: nation (Lane \& Potter, 2007; Li, Clark, Jensen, Yen, \& English, 2013; Schuitemaet al., 2013), state (Caulfield, 2012; Diamond, 2009) and city (Khan \& Kockelman, 2012). It is worth noting that studies on the adoption and influencing factors of EVs show that different countries or regions have heterogeneous characteristics due to their unique location attributes, resulting in significant differences in the adoption of EVs in countries or regions (Javid \& Nejat, 2017; Sierzchula, 2014; Sierzchula, Bakker, Maat, \& van Wee, 2014). For example, Javid and Nejat (2017) compared and analyzed the reasons for the differences in the adoption of EVs in different regions. They pointed out that the main differences of the important literatures on the adoption of EVs are: research region (country, state, province, city, etc.), research data (small sample survey data, large sample survey data or questionnaire survey data for traditional car buyers, etc.), research methods (least square method, statistical model and logit model), types of EVs (pure EVs, plug-in EVs and hybrid EVs), etc. It is found that a household's income, maximum level of education in the household, the buyer's car sharing status, charging stations density, and gas price in the region significantly affected the acceptance rate of EVs.

\subsection{Spatial Econometric Models}

Spatial econometric model, which can reflect the spatial effects of different countries or regions (usually including spatial interactions), and characterize the heterogeneity between countries or regions by appropriately setting the spatial weight matrix, is an excellent choice to study the spatial effect problems (Anselin, 1988; Elhorst, 2008; Gu et al., 2017; Zhu, Füss, \& Rottke, 2013). For example, Elhorst (2008) used numerical simulation methods to study the parameter estimation problem of residual terms in the regression model with both sequence correlation and spatial dependence. Gu et al. (2017) empirically studied the time-variant conditional correlation and contagion effects between the global real estate markets using a multivariate GARCH model with spatial effects. Zhu et al. (2013) used the dynamic spatial panel data model with GARCH terms to study the spatial interactions among the returns, residual disturbance terms and fluctuations of the housing market among 19 regions of the United States. The paper finds that the interaction between regional hosing markets in the United States from 1995 to 2009 is larger in both breadth and intensity than that between the earlier housing markets.

In general, the specification of spatial weight matrix reflects the possible relations between spatial locations in spatial econometrics. The accurate setting of spatial weight matrix has important influences on the estimation results of unknown parameters in spatial econometric models (Gu et al., 2017; Zhu et al., 2013). In order to properly set the spatial weight matrix and obtain reasonable parameter estimation results, this paper proposes a new construction method of economic spatial weight matrix by adopting the Mahalanobis distance and the variable bandwidth Gaussian kernel function. The spatial weight matrix characterizes the impacts of different indicators such as EV endurance mileage, power battery capacity, charging time, government subsidy, retail price, and each brand market share on EV sales. Finally, this paper explores the impacts of the per capita disposable income of urban households, gasoline price, loan rate and the number of charging pile on EV sales.

\subsection{Application of Spatial Econometric Models in the Field of Empirical Research on Electric Vehicles}

As one of the main documents of applying spatial econometric model to the field of empirical research on EVs, Adjemian, Cynthia Lin and Williams (2010) analyzed vehicle ownership based on census data by simultaneously controlling the spatial dependent parameters and related explanatory variables (such as income and population density) in the spatial econometric model.

Another representative paper that applies the spatial measurement model to the field of empirical research on 
EVs is Chen, Wang, and Kockelman (2015). The authors used the zone-level spatial count mode and the trivariate Poisson-lognormal conditional autoregressive model to study the influencing factors and spatial autocorrelation of EVs. The results show that high-income households in central urban areas have higher EV ownership rates; there is a positive correlation between EV ownership rate and the number of households and the number of workers in the household; the closer to the central city, the higher the ownership rate of EVs; there is a spatial autocorrelation between the ownership of EVs among families in different urban areas. This indicates that continuous penetration between markets will promote the purchase of EVs; the number of public EV charging station facilities will affect the market share of EVs in the surrounding areas to some extent; the neighborhood effect has an important impact on the purchase decision of the consumer. The ability to pay for EVs, the level of familiarity, and the convenience of using EVs are the important factors for consumers to choose to buy EVs.

In a recent study, Mukherjee and Ryan (2020) explored factors that influence early battery electric vehicle adoption in Ireland using spatial econometric analysis. The results reveal that the clustering characteristics of battery electric vehicle adopters are influenced by population as well as spillover effects. The adoption in neighboring localities, changes in socio-demographics and neighborhood characteristics are the main reasons that affect these spillover effects.

It should be noted that Adjemian et al. (2010) studied the factors affecting the adoption of EVs in countries or regions at a certain time. In other words, the paper uses a cross-sectional spatial econometric model to study related problems, and does not consider the change in the acceptance rate of the EVs connected to each other. This paper is based on the dynamic spatial panel data model proposed by Elhorst (2008) to empirically analyze the serial correlation and spatial heterogeneity among different brands of EV sales in China. The serial correlation is to describe the correlation between the EVs sales of an EV manufacturer in the period before and after; the spatial heterogeneity is mainly to study the reason why the sales of EVs of the different brand is different due to the performance of EVs or the operation ability and market competitiveness of the EV manufacturers.

\section{Model Specification and Estimation Methods}

To investigate the spatial correlation structures among different China's brands of pure EV sales, we use the spatial econometric models introduced by Elhorst (2008). The proposed model primarily builds on the following linear panel data regression model:

$$
y_{i t}=x_{i t} \beta+\varepsilon_{i t}, \quad i=1,2, \cdots N, t=1,2, \cdots T,
$$

where $y_{i t}$ denotes the sale observation on the $i$-th brand of pure EV at the $t$-th time period, $x_{i t}$ is an $l \times k$ vector of observations on the exogenous explanatory variables, $\beta$ is an $k \times 1$ vector of coefficients and $\varepsilon_{i t}$ is the regression disturbance. Let $y_{t}=\left(y_{1 t}, \cdots, y_{N t}\right)^{\prime}$ and $x_{t}=\left(x_{1 t}, \cdots, x_{N t}\right)^{\prime}$, the model in Eq. (1) can be rewritten more simply as

$$
y_{t}=x_{t} \beta+\varepsilon_{t}, \quad t=1,2, \mathrm{~L} T,
$$

where $\varepsilon_{t}=\left(\varepsilon_{1 t}, \mathrm{~L}, \varepsilon_{N t}\right)^{\prime}$ is the regression disturbance vector. Besides, to model spatial and temporal dependence among different China's brands of pure EV sales, we suppose the regression disturbance vector $\varepsilon_{t}$ in Eq. (2) is both serially and spatially autocorrelated. Specifically, $\varepsilon_{t}$ is assumed to follow the following spatial error processes constructed as in Eq. (3).

$$
\varepsilon_{t}=\lambda W \varepsilon_{t}+\rho \varepsilon_{t-1}+v_{t},
$$

where $W$ is an $N \times N$ known spatial weight matrix, $\lambda$ is the spatial dependence parameter with $|\lambda|<1, \rho$ is the serial correlation coefficient and satisfies the condition that $|\rho|<1, \rho \neq 0, v_{t}=\left(v_{1 t}, \cdots, v_{N t}\right)$ is an $N \times 1$ error vector assumed to be independently and identically distributed across a cross-sectional dimension with zero mean and constant variance $\sigma^{2} I_{N}$ and $I_{N}$ is an identity matrix of dimension $N$.

Let $B=I_{N}-\lambda W$, the model in Eq. (3) can be rewritten as

$$
B \varepsilon_{t}=\rho \varepsilon_{t-1}+v_{t},
$$

The model in Eq. (4) can be rewritten as

$$
B \varepsilon_{t}=v_{t}+\sum_{m=1}^{\infty} \rho^{m} B^{-m} v_{t-m}
$$

Suppose $B$ is nonsingular matrix, then $E\left(B \varepsilon_{t}\right)=0$ and $\operatorname{Var}\left(B \varepsilon_{t}\right)$ can be described as

$$
\operatorname{Var}\left(B \varepsilon_{t}\right)=E\left(v_{t} v_{t}^{\prime}\right)+\sum_{m=1}^{\infty} \rho^{2 m} B^{-m} E\left(v_{t-m} v_{t-m}^{\prime}\right) B^{\prime-m}=\sigma^{2}\left(I_{N}-\rho^{2} B^{-1} B^{\prime-1}\right)^{-1},
$$

Because $\operatorname{Var}\left(v_{t}\right)=\sigma^{2} I_{N}, y_{t}=x_{t} \beta+\varepsilon_{t}, \operatorname{Var}\left(\varepsilon_{t}\right)=\sigma^{2} B^{-1}\left(I_{N}-\rho^{2} B^{-1} B^{\prime-1}\right)^{-1} B^{\prime-1}$ according to Eq. (6), then we get 
Eq.(7):

$$
\begin{array}{ll}
S B y_{1}=S B x_{1} \beta+v_{1}, & \text { if } t=1 \\
B y_{t}=B x_{t} \beta+\rho y_{t-1}-\rho x_{t-1} \beta+v_{t}, & \text { if } t>1
\end{array}
$$

where $S$ is a positive definite matrix subject to (s.t.) $S^{\prime} S=I_{N}-\rho^{2} B^{-1} B^{\prime-1}$.

Therefore, under the assumption of normality, the log-likelihood functions for $y=\left(y_{1}^{\prime}, \mathrm{L}, y_{T}^{\prime}\right)^{\prime}$ is:

$$
\begin{aligned}
& \operatorname{Ln} L\left(\lambda, \rho, \beta, \sigma^{2}\right) \\
= & -\frac{N T}{2} \ln \left(2 \pi \sigma^{2}\right)+\frac{N}{2} \ln |P|+T \ln |B|-\frac{1}{2 \sigma^{2}}\left(\left(y_{1}-x_{1} \beta\right)^{\prime}(B)^{\prime} S^{\prime} S B\left(y_{1}-x_{1} \beta\right)\right), \\
& -\frac{1}{2 \sigma^{2}} \sum_{t=2}^{T}\left(\left(B y_{t}-B x_{t} \beta-\rho y_{t-1}+\rho x_{t-1} \beta\right)^{\prime} \times\left(B y_{t}-B x_{t} \beta-\rho y_{t-1}+\rho x_{t-1} \beta\right)\right)
\end{aligned}
$$

To estimate Eq. (8), we can first define the observations in Eq. (7) as

$$
\begin{array}{ll}
y_{1}^{*}=S B y_{1}, x_{1}^{*}=S B x_{1}, & \text { if } t=1 \\
y_{t}^{*}=B y_{t}-\rho y_{t-1}, x_{t}^{*}=B x_{t}-\rho x_{t-1}, & \text { if } t>1
\end{array}
$$

Then, for the entire sample of size $T$, the model in Eq. (7) can be further expressed compactly in the matrix notation as in Eq. (10) if the observations are ordered with $t$ being the slow running index and $i$ the fast running index.

$$
y^{*}=x^{*} \beta+v,
$$

where $y^{*}=\left(y_{1}^{* \prime}, \mathrm{L}, y_{T}^{* \prime}\right)^{\prime}$ is an $N T \times 1$ vector, $x^{*}=\left(x_{1}^{* \prime}, \mathrm{L}, x_{T}^{* \prime}\right)^{\prime}$ is an $N T \times k$ matrix, and $v=\left(v_{1}^{\prime}, \mathrm{L}, v_{T}^{\prime}\right)^{\prime}$ is an $N T \times 1$ error vector.

Therefore, we can use the ordinary least square (OLS) method to estimate Eq. (10) and get

$$
\hat{\beta}=\left(x^{* \prime} x^{*}\right)^{-1} x^{* \prime \prime} y^{*}, \hat{\sigma}^{2}=\frac{1}{N T}\left(y^{*}-x^{*} \hat{\beta}\right)^{\prime}\left(y^{*}-x^{*} \hat{\beta}\right),
$$

Once we obtain Eq. (11) and get the estimators of $\hat{\beta}$ and $\hat{\sigma}^{2}$, then we can estimate $\lambda$ and $\rho$ by the following models:

$$
(\hat{\lambda}, \hat{\rho})=\underset{\lambda, \rho}{\arg \max } \operatorname{LnL}\left(\lambda, \rho, \hat{\beta}, \hat{\sigma}^{2}\right)
$$

\section{Empirical Illustrations}

\subsection{Data Sources and Description}

According to the China Passenger Car Association (CPCA), at the end of 2018, China's new energy passenger vehicles sold units in 1,052,951, an increase of 61.67 percent as compared with that at the end of 2017. The pure EVs sold units in 787,732, up by 68.32 percent compared with the previous year. The plug-in hybrid EVs sold units in 265,219, up by 138.94 percent compared with the previous year. Therefore, pure EVs still dominate the new energy vehicle market. From the perspective of the EV manufacturer, the Beijing Electric Vehicle Company Limited (BAIC) took the first place in pure EV sales and sold units 127,980 in 2018, and the main brands include BAIC EC, BAIC EU and BAIC EX. The BYD Co., Ltd. (BYD) took the second place in pure EV sales and sold units 63,248 in 2018 and the main brands include BYD E5 and E6. China's top 10 best-selling pure EV brands in 2018 are shown in Figure 1.

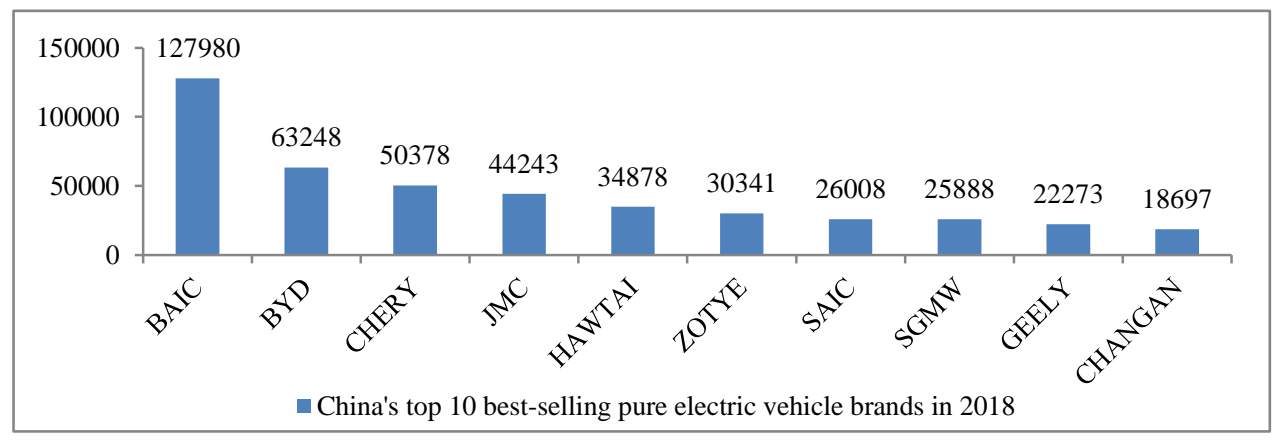

Figure 1. China's top 10 best-selling pure EV brands in 2018 
As shown in Figure 1, China's top 10 best-selling pure EV brands sold units in 443,934 and had 56.36 percent market share in the new energy vehicle market. Thus, we choose the top 10 best-selling pure EV manufacturer sales to empirically investigate the spatial and serial correlation structures among them and discuss whether EV endurance mileage, power battery capacity, charging time, government subsidy, retail price, and each market share have important impacts on EV sales.

Monthly pure EV sales data of the 10 manufacturers are obtained from Wind financial database from January 2015 to October 2019. This database is a famous economic database containing most of the historical and recent data for Chinese macro, industry and firms. Specifically, the 10 manufacturers are Beijing Electric Vehicle Company Limited (BAIC), Build Your Dream Co., Ltd. (BYD), Jiangling Motors Co., Ltd. (JMC), Zotye Automobile Co., Ltd. (ZOTYE), Geely Automobile Holding Group (GEELY), ZHIDOU Electric Vehicle Co., Ltd. (ZHIDOU), Jianghuai Automobile Co., Ltd. (JAC), Chery Automobile Co., Ltd. (CHERY), Chongqing Changan Automobile Co., Ltd. (CHANGAN), Shenzhen BYD Daimler New Technology Co., Ltd. (DENZA), and SAIC Motor Co., Ltd. (SAIC).

Table 1 below presents some description statistics of different brands of pure EV sales. As shown in Table 1, all the kurtoses are bigger than 2 and most of the Jarque-Bera statistics are significantly different from 0 at the $1 \%$ significance level. These results indicate that the distribution of the series is not normal distribution but is characterized by fat-tails.

Table 1. Description statistics of different brands of pure EV sales

\begin{tabular}{lcccccccc}
\hline Brand & Mean & Median & Max. & Min. & SD & Skewness & Kurtosis & Jarque-Bera \\
\hline BYD & 11581.67 & 8830.50 & 37010.00 & 605.00 & 8130.63 & 1.13 & 3.68 & $13.52^{* * *}$ \\
BAIC & 6155.29 & 3902.00 & 24723.00 & 132.00 & 6116.08 & 1.39 & 4.10 & $21.67^{* * *}$ \\
ZOTYE & 2434.45 & 2216.00 & 11163.00 & 187.00 & 2021.82 & 1.67 & 7.64 & $78.93^{* * *}$ \\
GEELY & 1831.85 & 1541.50 & 6023.00 & 0.00 & 1599.34 & 0.61 & 2.40 & 4.47 \\
ZHIDOU & 1592.90 & 672.50 & 6164.00 & 0.00 & 1813.97 & 0.90 & 2.41 & $8.72^{* * *}$ \\
JAC & 2988.81 & 2174.00 & 11182.00 & 0.00 & 2530.33 & 1.25 & 4.08 & $18.04^{* * *}$ \\
CHERY & 2392.31 & 2187.50 & 6616.00 & 182.00 & 1773.16 & 0.58 & 2.44 & 4.01 \\
CHANGAN & 3637.10 & 2847.50 & 21204.00 & 0.00 & 3733.97 & 2.18 & 9.88 & $160.18^{* * *}$ \\
DENZA & 240.53 & 131.50 & 1859.00 & 0.00 & 340.94 & 2.64 & 10.99 & $221.98^{* * *}$ \\
SAIC & 2633.33 & 804.50 & 22261.00 & 0.00 & 4905.97 & 2.83 & 10.26 & $204.83^{* * *}$ \\
\hline
\end{tabular}

Note. The columns provide arithmetic mean, median, maximum, minimum, standard deviation (SD), skewness, kurtosis, Jarque-Bera test. ${ }^{* * *}$, ** and ${ }^{*}$ represent statistical significance at the $1 \%, 5 \%$, and $10 \%$ levels, respectively.

Table 2 presents the correlation matrix for the time series of monthly pure EV sales for 10 different EV manufacturers. The results show that most correlation coefficients between each two EV manufacturers are positive. In general, the correlation coefficients between two EV manufacturers with closer economic distances are larger than those between EV manufacturers with farther economic distances. For example, the correlation coefficient between BAIC and BYD reaches up to 0.734. One reason for such a situation may be that the characteristics of pure EV, such as endurance mileage, power battery capacity, charging time, which is produced by BAIC, is similar to that of BYD. This emphasizes that the spatial weight matrix is a core element to reflect the possible relations between spatial units and the estimation bias will occur when estimating spatial econometric models by ignoring the appropriate choice of the spatial weight matrix.

Table 2. Correlation matrix of different brands of pure EV sales

\begin{tabular}{llllllllll}
\hline Brand & BAIC & ZOTYE & GEELY & ZHIDOU & JAC & CHERY & CHANGAN & DENZA & SAIC \\
\hline BYD & $0.734^{* * *}$ & -0.039 & $0.611^{* * *}$ & -0.140 & $0.909^{* * *}$ & $0.832^{* * *}$ & $0.717^{* * *}$ & 0.172 & $0.771^{* * *}$ \\
BAIC & & 0.115 & $0.462^{* * *}$ & 0.019 & $0.739^{* * *}$ & $0.721^{* * *}$ & $0.757^{* * *}$ & $0.229^{*}$ & $0.375^{* * *}$ \\
ZOTYE & & & 0.172 & $0.385^{* * *}$ & -0.062 & 0.165 & $0.308^{* *}$ & $0.344^{* * *}$ & -0.110 \\
GEELY & & & & 0.099 & $0.579^{* * *}$ & $0.654^{* * *}$ & $0.516^{* * *}$ & 0.189 & $0.431^{* * *}$ \\
ZHIDOU & & & & & -0.122 & 0.009 & 0.164 & $0.251^{*}$ & $-0.220^{*}$ \\
JAC & & & & & & $0.787^{* * *}$ & $0.695^{* * *}$ & $0.228^{*}$ & $0.656^{* * *}$ \\
CHERY & & & & & & $0.737^{* * *}$ & 0.205 & $0.421^{* * *}$ \\
CHANGAN & & & & & & & $0.411^{* * *}$ & $0.470^{* * *}$ \\
DENZA & & & & & & & & & 0.060 \\
\hline
\end{tabular}

Note. ${ }^{* * *},{ }^{* *}$, and ${ }^{*}$ represent statistical significance at the $1 \%, 5 \%$, and $10 \%$ levels, respectively. 
In this study, the main explanatory variables contain the per capita disposable income of urban households, fixed vehicle loan rate, gasoline price, and the number of charging pile. The data are obtained from Wind financial database. We regard the loan rate with an over three-year maturity and under five-year maturity as proxy for the fixed vehicle loan rate because the fixed vehicle rate is generally in accordance with the bank benchmark loan rate with an over three-year maturity and under five-year maturity in China, and this loan rate is set by the People's Bank of China (PBC). Because we only have quarterly data for the per capita disposable income of urban households, we transform it into monthly data using quadratic-match sum conversion method through Eviews 8. The selection of these control variables is mainly based on insights from well-established literature that explore potential factors that can be attributed to purchasing EVs. For example, Javid and Nejat (2017) explored the factors that are deemed to be associated with plug-in EV adoption. The study finds that potential factors that affect plug-in EV purchasing behavior can be classified into three main categories: vehicle-related factors such as the gas fuel vehicles, pure EVs, or hybrid EVs, consumer-related factors such as socioeconomics characteristics of household including household size, the number of vehicle in a household, the maximum level of education, and household income, demographic characteristics of individuals including age and gender, and market factors such as gas and electricity price, the infrastructures including the number of charging stations and the cost of charging, and the population density.

\subsection{Specifications of Economic Spatial Weight Matrices}

The spatial weight matrix is a core element to reflect the possible relations between spatial locations in spatial econometrics field. In general, a spatial weight matrix is defined as a spatial correlation function of geographic distance, economic distance, or social distance between cross-sectional units (Gu et al., 2017; Zhu et al., 2013).

Since the aim of this study is to empirically investigate the spatial correlation structures among different China's brands of pure EV sales, an economic spatial weight matrix that can reflect economic linkages between EV manufacturers will be a reasonable choice. Thus, we follow the work of $\mathrm{Gu}$ et al. (2017) and adopt the Mahalanobis distance to construct our economic spatial weight matrix using the characteristics of EV relevant indicators.

Particularly, the element in the economic spatial weight matrix is defined as follows:

$$
w_{i j}= \begin{cases}\exp \left\{-\left[d_{i j} / \bar{d}\right]^{2}\right\}, & \text { if } i \neq j, \\ 1, & \text { if } i=j\end{cases}
$$

where $w_{i j}$ represents the weight between manufacture $i$ and manufacture $j, d_{i j}$ represents the economics distance between manufacture $i$ and manufacture $j, \bar{d}=h\left(d_{i j}\right)$ represents a non-negative bandwidth kernel function. We follow the work of Gu et al. (2017) and adopt the Mahalanobis distance to define $d_{i j}$. The Mahalanobis distance is defined as: $d_{i j}=\sqrt{\left(E_{i}-E_{j}\right)^{\prime} V^{-1}\left(E_{i}-E_{j}\right)}$, where $E_{i}$ and $E_{j}$ denotes the characteristics of EV relevant indicators produced by manufacture $i$ and manufacture $j$, respectively. $V$ denotes the sample variance-covariance matrix and $V^{-1}$ is the inverse matrix of $V$. Particularly, we use indicators such as EV endurance mileage; power battery capacity; charging time; government subsidy; no subsidized retail price; and each brand market share to explore the factors that are deemed to be associated with EV sales (see Table 3). In general, the central government and local governments subsidize 45,000 Yuan for each EV. The Mahalanobis distances among different brands of pure EV are described in Table 4.

Table 3. Summary statistics

\begin{tabular}{lllllll}
\hline Brand & $\begin{array}{l}\text { Endurance } \\
\text { mileage/KM }\end{array}$ & $\begin{array}{l}\text { Power battery } \\
\text { capacity/kWh }\end{array}$ & $\begin{array}{l}\text { Fast charging } \\
\text { time/hour }\end{array}$ & $\begin{array}{l}\text { Slow charging } \\
\text { time/hour }\end{array}$ & $\begin{array}{l}\text { Non-subsidized } \\
\text { price/thousand Yuan }\end{array}$ & $\begin{array}{l}\text { Market } \\
\text { share/\% }\end{array}$ \\
\hline BYD & 305 & 43.00 & 2.00 & 9.50 & 129.8 & 19.72 \\
BAIC & 200 & 30.40 & 0.50 & 8.50 & 66.9 & 8.92 \\
ZOTYE & 185 & 24.50 & 0.63 & 7.00 & 91.8 & 6.85 \\
GEELY & 253 & 45.30 & 0.80 & 14.00 & 118.8 & 2.88 \\
ZHIDOU & 155 & 18.00 & 1.25 & 7.00 & 68.8 & 3.42 \\
JAC & 200 & 23.00 & 2.50 & 8.00 & 89.8 & 4.54 \\
CHERY & 200 & 22.30 & 0.50 & 9.00 & 69.9 & 3.69 \\
CHANGAN & 240 & 26.00 & 0.50 & 8.00 & 59.9 & 5.40 \\
DENZA & 253 & 47.50 & 1.00 & 32.00 & 261.0 & 0.44 \\
SAIC & 405 & 16.00 & 3.00 & 7.00 & 278.8 & 3.85 \\
\hline
\end{tabular}

Note. The market share is the monthly average proportion value of each pure EV brand sale in China's total pure EV brand sale covering the period from January 2015 to October 2019. 
Table 4. Mahalanobis distance among different brands of pure EV

\begin{tabular}{lllllllllll}
\hline Brand & BYD & BAIC & ZOTYE & GEELY & ZHIDOU & JAC & CHERY & CHANGAN & DENZA & SAIC \\
\hline BYD & 0.000 & 2.710 & 3.568 & 4.218 & 3.852 & 3.759 & 3.654 & 3.765 & 4.135 & 4.126 \\
BAIC & 2.710 & 0.000 & 1.478 & 3.179 & 2.108 & 3.389 & 1.621 & 2.425 & 3.363 & 3.567 \\
ZOTYE & 3.568 & 1.478 & 0.000 & 3.547 & 1.907 & 3.971 & 2.587 & 3.642 & 3.784 & 3.530 \\
GEELY & 4.218 & 3.179 & 3.547 & 0.000 & 3.806 & 3.888 & 3.659 & 3.756 & 4.189 & 4.206 \\
ZHIDOU & 3.852 & 2.108 & 1.907 & 3.806 & 0.000 & 2.516 & 2.400 & 3.561 & 3.633 & 3.710 \\
JAC & 3.759 & 3.389 & 3.971 & 3.888 & 2.516 & 0.000 & 3.177 & 3.580 & 4.061 & 3.990 \\
CHERY & 3.654 & 1.621 & 2.587 & 3.659 & 2.400 & 3.177 & 0.000 & 1.343 & 3.328 & 3.450 \\
CHANGAN & 3.765 & 2.425 & 3.642 & 3.756 & 3.561 & 3.580 & 1.343 & 0.000 & 3.954 & 3.803 \\
DENZA & 4.135 & 3.363 & 3.784 & 4.189 & 3.633 & 4.061 & 3.328 & 3.954 & 0.000 & 4.216 \\
SAIC & 4.126 & 3.567 & 3.530 & 4.206 & 3.710 & 3.990 & 3.450 & 3.803 & 4.216 & 0.000 \\
\hline
\end{tabular}

\subsection{Estimation Results}

Table 5 presents the regression results. In Specification 1, we adopt the ordinary least square (OLS) method to estimate the parameters. In Specification 2, we allow for incorporating the serial dependence into the proposed model. The two specifications are our benchmark models. Specifications 3 and 4 are our proposed models using another two different spatial weight matrices. Particularly, Specification 3 uses the squared kernel function to construct the economic spatial weight matrix and Specification 4 adopts the exponential kernel function to construct the economic spatial weight matrix (see the notes in Table 5). Specification 5 is our proposed model estimation results.

Table 5. Estimation results of various models

\begin{tabular}{|c|c|c|c|c|c|c|c|c|c|c|}
\hline Parameter & Specificat & & Specificat & & Specifica & & Specifica & & Specifica & \\
\hline & Estimate & S.E. & Estimate & S.E. & Estimate & S.E. & Estimate & S.E. & Estimate & S.E. \\
\hline$\beta_{0}$ & $19.891^{* * *}$ & 2.630 & $17.259^{* * *}$ & 4.800 & $14.371^{*}$ & 7.887 & $16.801^{* * *}$ & 5.584 & $16.801^{* * *}$ & 5.584 \\
\hline$\beta_{\text {income }}$ & $-3.455^{* *}$ & 1.362 & $-3.144^{* * * *}$ & 0.829 & $-3.140^{* * *}$ & 0.945 & $-3.150^{* * *}$ & 0.889 & $-3.150^{* * *}$ & 0.889 \\
\hline$\beta_{\text {rate }}$ & $-8.197^{* * *}$ & 1.665 & $-6.724^{* *}$ & 3.015 & -5.379 & 4.897 & $-6.460^{*}$ & 3.502 & $-6.460^{*}$ & 3.502 \\
\hline$\beta_{\text {gas }}$ & 0.840 & 1.757 & $1.782^{*}$ & 0.995 & 1.654 & 1.134 & $1.765^{*}$ & 1.066 & $1.765^{*}$ & 1.066 \\
\hline$\beta_{\text {charging }}$ & -0.664 & 2.774 & $2.755^{*}$ & 1.523 & $3.010^{*}$ & 1.720 & $2.796^{*}$ & 1.628 & $2.796^{*}$ & 1.628 \\
\hline $\bar{d}$ & - & - & - & - & $4.218^{* * *}$ & 0.224 & $0.655^{* * *}$ & 0.028 & $0.927^{* * *}$ & 0.039 \\
\hline$\rho$ & - & - & 0.772 & 1.000 & $0.624^{* * * *}$ & 0.038 & $0.188^{* * *}$ & 0.020 & $0.188^{* * *}$ & 0.020 \\
\hline$\lambda$ & - & - & - & - & $0.317^{* * * *}$ & 0.054 & $0.766^{* * *}$ & 0.019 & $0.766^{* * *}$ & 0.019 \\
\hline$\sigma^{2}$ & 5.508 & & 0.154 & & 1.621 & & 0.154 & & 0.154 & \\
\hline$R^{2}$ & 0.06 & & 0.07 & & 0.04 & & 0.07 & & 0.07 & \\
\hline$M L$ & -1315.17 & & -1054.51 & & -1066.46 & & -1054.51 & & -1054.51 & \\
\hline RMSE & 2.347 & & 0.392 & & 1.273 & & 0.392 & & 0.392 & \\
\hline
\end{tabular}

Note. Parameters $\beta_{\text {income }}, \beta_{\text {rate }}, \beta_{\text {gas }}$ and $\beta_{\text {charg ing }}$ represent coefficients of the per capita disposable income of urban households, loan rate, gasoline price, and the number of charging pile. Specification 3 bases on the kernel function: $w_{i j}=\left[1-\left(d_{i j} / \bar{d}\right)^{2}\right]^{2}$ if $i \neq j$; otherwise $w_{i j}=1$. Specification 4 bases on the kernel function: $w_{i j}=\exp \left\{-\frac{1}{2}\left(d_{i j} / \bar{d}\right)^{2}\right\}$ if $i \neq j$; otherwise $w_{i j}=1$. S.E. represents standard errors of the estimated parameters. $M L$ represents $\log$-likelihood. $R^{2}$ is the goodness-of-fit. The unit of $\sigma^{2}$ is in percentage. ${ }^{* * *},{ }^{* *}$, and ${ }^{*}$ represent statistical significance at the $1 \%, 5 \%$, and $10 \%$ levels, respectively.

The results show that all the explanatory variables that are statistically significant have reasonable signs. Particularly, the per capita disposable income of urban households and the loan rate are significantly negatively correlated with EV sales. Meanwhile, the number of charging pile and the gasoline price are significantly negatively correlated with EV sales.

Because the explanatory variables are in the form of logarithmic differences, for instance, the parameter $\beta_{\text {income }}=-3.150$ implies that the per capita disposable income of urban household's increases 1 percent, the EV 
sales will decrease 3.150 percent. A plausible explanation would seem to be that the impact of the per capita disposable income of urban households on the EV sales is offset by the decline in government subsidies or the incomplete infrastructures such as the inconvenient of charging stations. Similarly, the parameter $\beta_{\text {rate }}=-6.460$ shows that one percent of the rise of loan rate will lead to 6.460 percent decrease of EV sales. The parameter $\beta_{\text {gas }}=1.765$ shows that one percent of the gasoline price will lead to 1.765 percent increase of EV sales. The parameter $\beta_{\text {charging }}=2.796$ indicates that one percent of the improvements of the number of charging pile will lead to 2.796 percent increase of $\mathrm{EV}$ sales.

Furthermore, the coefficients of spatial dependence and serial correlation parameters are statistically significantly different from zero. The absolute value of spatial dependence parameter $\lambda$ is much larger than that of serial correlation parameter $\rho$. This fact suggests that both the spatial dependence and serial correlation exist among EV manufactures; the intensity of spatial dependence is stronger than the intensity of serial correlation. The significantly positive serial correlation indicates the previous EV sales data is useful for later sales. Moreover, the significantly positive spatial dependence implies that spatial interactions exist among EV manufactures due to the similar EV economic characteristics such as EV endurance mileage, power battery capacity, charging time, government subsidy, retail price, and each brand market share, etc. Thus, when developing EV sales strategies, EV manufacturers must consider not only the properties of the EVs they produce, but also the properties of similar types of EVs produced by other brands in the EV market.

\section{Conclusion}

This paper empirically investigates the spatial dependence and serial correlation structures among ten China's brands of pure EV sales using spatial econometric models. Following the work of Gu et al. (2017), this study proposes a new construction method of economic spatial weight matrix by adopting the Mahalanobis distance and the variable bandwidth Gaussian kernel function. We use the proposed economic spatial weight matrix to explore the impacts of EV endurance mileage, power battery capacity, charging time, government subsidy, retail price, and each brand market share on EV sales. Based on the proposed models, we also discuss the impacts of the per capita disposable income of urban households, gasoline price, loan rate and the number of charging pile on EV sales.

The main findings are presented as follows. First, the results show that the loan rate is significantly negatively correlated with EV sales. Meanwhile, the number of charging pile and the gasoline price are significantly negatively correlated with EV sales. In other words, the improvements of the number of charging pile and the rise of gasoline price can increase EV sales, while the rise of loan rate or tight monetary policy may increase the consumers' cost of purchasing EVs and then decrease EV sales. These findings are in accordance with those of Chen et al. (2015), Gallagher and Muehlegger (2011). Second, an interesting finding is that though the per capita disposable income of urban households increases the EV sales decreases. A plausible explanation would seem to be that the impact of the per capita disposable income of urban households on the EV sales is offset by the decline in government subsidies or the incomplete infrastructures such as the inconvenient of charging stations. Third, the significantly positive serial correlation indicates the previous EV sales data is useful for later sales. Moreover, the significantly positive spatial dependence implies that spatial interactions exist among EV manufactures due to the similar EV economic characteristics such as EV endurance mileage, power battery capacity, charging time, government subsidy, retail price, and each brand market share, etc.

We believe that the empirical findings provide important implications on the sales strategies of EV manufacturers' and the development of EV market. First, the important implication of the above findings for government is that government should pursue prudent and balanced monetary policy and provide reasonable EV subsidy policy in order to promote the healthy development of EV market. Second, when developing EV production and sales strategies, EV manufacturers must consider not only the properties of the EVs they produce, but also the properties of similar types of EVs produced by other brands in the EV market.

There are two limitations of this study. One is the sample selection has certain limitations. Limited by the availability of data, this paper selects the monthly pure EV sales data of the 10 manufactures in China from January 2015 to October 2019. The sample period is very short, which may lead to low accuracy of the obtained parameter estimation results. In order to obtain the robust parameter estimation results under the condition of finite samples, the paper discusses in detail how to construct the economic spatial weight matrix and how to setup the initial value of parameters. Another limitation is the measurement of explanatory variables. The paper only discusses the influences of the per capita disposable income of urban households, the loan rate and the 
gasoline price on EV sales. Therefore, in the future research, it is also possible to consider the number of EV charging piles, electricity price, government subsidies and other factors that affect EV sales. In addition, in the future research, the proposed models can be applied to model the dependence structure of other kinds of EV markets (e.g., EVs in different countries, different brands of hybrid EVs) based on using copula function families (e.g., C-vine, D-vine and R-vine copulas) to construct the economic spatial weight matrix.

\section{References}

Adjemian, M. K., Cynthia Lin, C. Y., \& Williams, J. (2010). Estimating spatial interdependence in automobile type choice with survey data. Transportation Research Part A: Policy and Practice, 44(9), 661-675. https://doi.org/10.1016/j.tra.2010.06.001

Ahmadi, L., Yip, A., Fowler, M., Young, S. B., \& Fraser, R. A. (2014). Environmental feasibility of re-use of electric vehicle batteries. Sustainable Energy Technologies and Assessments, 6, 64-74. https://doi.org/10.1016/j.seta.2014.01.006

Anselin, L. (1988). Spatial econometrics: methods and models. Dordrecht: Kluwer.

Avci, B., Girotra, K., \& Netessine, S. (2014). Electric Vehicles with a Battery Switching Station: Adoption and Environmental Impact. Management Science, 61(4), 772-794. https://doi.org/10.1287/mnsc.2014.1916

Carley, S., Krause, R. M., Lane, B. W., \& Graham, J. D. (2013). Intent to purchase a plug-in electric vehicle: A survey of early impressions in large US cites. Transportation Research Part D: Transport and Environment, 18, 39-45. https://doi.org/10.1016/j.trd.2012.09.007

Caulfield, B. (2012). An examination of the factors that impact upon multiple vehicle ownership: The case of Dublin, Ireland. Transport Policy, 19(1), 132-138. https://doi.org/10.1016/j.tranpol.2011.08.003

Chen, T. D., Wang, Y., \& Kockelman, K. M. (2015). Where are the electric vehicles? A spatial model for vehicle-choice count data. Journal of Transport Geography, 43, 181-188. https://doi.org/10.1016/j.jtrangeo.2015.02.005

Diamond, D. (2009). The impact of government incentives for hybrid-electric vehicles: Evidence from US states. Energy Policy, 37(3), 972-983. https://doi.org/10.1016/j.enpol.2008.09.094

Elhorst, J. P. (2008). Serial and spatial error correlation. Economics Letters, 100(3), 422-424. https://doi.org/10.1016/j.econlet.2008.03.009

Gallagher, K. S., \& Muehlegger, E. (2011). Giving green to get green? Incentives and consumer adoption of hybrid vehicle technology. Journal of Environmental Economics and Management, 61(1), 1-15. https://doi.org/10.1016/j.jeem.2010.05.004

Gu, H., Liu, Z., \& Weng, Y. (2017). Time-varying correlations in global real estate markets: A multivariate GARCH with spatial effects approach. Physica A: Statistical Mechanics and Its Applications, 471, 460-472. https://doi.org/10.1016/j.physa.2016.12.056

Heymans, C., Walker, S. B., Young, S. B., \& Fowler, M. (2014). Economic analysis of second use electric vehicle batteries for residential energy storage and load-levelling. Energy Policy, 71, 22-30. https://doi.org/10.1016/j.enpol.2014.04.016

Javid, R. J., \& Nejat, A. (2017). A comprehensive model of regional electric vehicle adoption and penetration. Transport Policy, 54, 30-42. https://doi.org/10.1016/j.tranpol.2016.11.003

Khan, M., \& Kockelman, K. M. (2012). Predicting the market potential of plug-in electric vehicles using multiday GPS data. Energy Policy, 46, 225-233. https://doi.org/10.1016/j.enpol.2012.03.055

Lane, B., \& Potter, S. (2007). The adoption of cleaner vehicles in the UK: exploring the consumer attitudeaction gap. Journal of Cleaner Production, 15(11-12), 1085-1092. https://doi.org/10.1016/j.jclepro.2006.05.026

Li, X., Clark, C. D., Jensen, K. L., Yen, S. T., \& English, B. C. (2013). Consumer purchase intentions for flexible-fuel and hybrid-electric vehicles. Transportation Research Part D: Transport and Environment, 18, 9-15. https://doi.org/10.1016/j.trd.2012.08.001

Mukherjee, S. C., \& Ryan, L. (2020). Factors influencing early battery electric vehicle adoption in Ireland. Renewable and Sustainable Energy Reviews, 118, 109504. https://doi.org/10.1016/j.rser.2019.109504

Neubauer, J., \& Pesaran, A. (2011). The ability of battery second use strategies to impact plug-in electric vehicle prices and serve utility energy storage applications. Journal of Power Sources, 196(23), 10351-10358. 
https://doi.org/10.1016/j.jpowsour.2011.06.053

Schuitema, G., Anable, J., Skippon, S., \& Kinnear, N. (2013). The role of instrumental, hedonic and symbolic attributes in the intention to adopt electric vehicles. Transportation Research Part A: Policy and Practice, 48, 39-49. https://doi.org/10.1016/j.tra.2012.10.004

Sierzchula, W. (2014). Factors influencing fleet manager adoption of electric vehicles. Transportation Research Part D: Transport and Environment, 31, 126-134. https://doi.org/10.1016/j.trd.2014.05.022

Sierzchula, W., Bakker, S., Maat, K., \& van Wee, B. (2014). The influence of financial incentives and other socio-economic factors on electric vehicle adoption. Energy Policy, 68, 183-194. https://doi.org/10.1016/j.enpol.2014.01.043

Smith, M. (2009). Batteries versus biomass as a transport solution. Nature, 457(7231), 785. https://doi.org/10.1038/457785d

Zhu, B., Füss, R., \& Rottke, N. B. (2013). Spatial Linkages in Returns and Volatilities among U.S. Regional Housing Markets. Real Estate Economics, 41(1), 29-64. https://doi.org/10.1111/j.1540-6229.2012.00337.X

\section{Copyrights}

Copyright for this article is retained by the author(s), with first publication rights granted to the journal.

This is an open-access article distributed under the terms and conditions of the Creative Commons Attribution license (http://creativecommons.org/licenses/by/4.0/). 